\title{
Predicting the Course of Graves' Orbitopathy Using Serially Measured TSH-Receptor Autoantibodies by Automated Binding Immunoassays and the Functional Bioassay
}

\author{
Authors \\ Mareile Stöhr ${ }^{1}$, Michael Oeverhaus ${ }^{1}$, Simon D. Lytton², Mareike Horstmann¹, Denise Zwanziger ${ }^{3}$, Lars Möller ${ }^{3}$, \\ Achim Stark ${ }^{4}$, Dagmar Führer-Sakel ${ }^{3}$, Nikolaos Bechrakis', Utta Berchner-Pfannschmidt ${ }^{3}$, J. Paul Banga ${ }^{5}$, \\ Svenja Philipp ${ }^{3 *}$, Anja Eckstein ${ }^{*}$
}

\author{
Affiliations \\ 1 Department of Ophthalmology, University Hospital \\ Essen, Essen, Germany \\ 2 SeraDiaLogistics, Munich, Germany \\ 3 Department of Endocrinology, Diabetes and Metabolism, \\ Division of Laboratory Research, University of Duisburg- \\ Essen, Essen, Germany \\ 4 Practice for General Medicine, Essen, Germany \\ 5 Emeritus, King's College London, London, UK
}

\begin{abstract}
Key words Graves' orbitopathy, TSH-receptor antibodies, functional antibodies, binding assays, bioassays
\end{abstract}

received 12.04 .2021

accepted after revision $\quad$ 01.06.2021

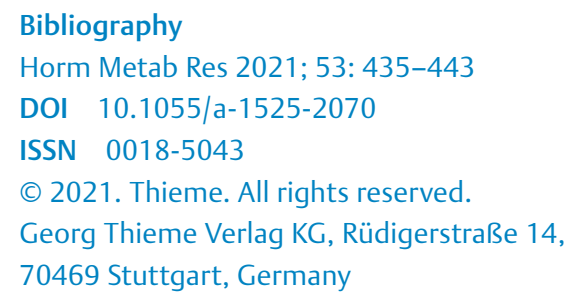

Mareile.stoehr@uk-essen.de

\begin{abstract}
The aim of the study was to investigate the use of serial measurements of TSH-receptor autoantibodies (TRAb) with the newest available assay technology to predict the course of Graves' Orbitopathy (GO) during the first 24 months from disease onset. Serial serum samples from patients with GO (103 mild/135 severe) were collected between 2007 and 2017 and retrospectively analyzed. The course of $\mathrm{GO}$ were classified into mild/severe 12 months after manifestation (severe: NOSPECS $\geq 5$; mild $<5$ ). TRAb were measured with automated binding immunoassays (IU/I): TRAb Elecsys (Cobas, Roche), TRAb bridge assay (IMMULITE, Siemens), and a cell-based bioassay (percent of specimen to reference ratio - SRR \%) (Thyretain, Quidel). Variable cut off levels of measured TRAb were calculated at specificity of $90 \%$ from receiver operator curve (ROC) analysis for several timepoints during the course of GO. To select one: 5-8 months after first GO symptoms, which is the timepoint for usual referals for treatment mild course could be predicted at cut offs of $1.5 \mathrm{IU} / \mathrm{I}$ (Elecsys), $0.8 \mathrm{IU} / \mathrm{I}$ (Immulite) and $402 \%$ SRR (Thyretain) and the risc of severe course has to be anticipated if TRAb are above $11.6 \mathrm{IU} / \mathrm{l}$ (Elecsys), $6.5 \mathrm{IU} / \mathrm{I}$ (Thyretain), and 714\% SRR (Thyretain). The Thyretain bioassay showed the highest diagnostic sensitivity (using the commercial cut off's) over the entire follow up period. TRAb measurements during the 24-month follow up of GO provide added value to the GO clinical activity and severity scores and should be used especially in the event of an unclear decision-taking situation with regard to therapy.
\end{abstract}

\section{Introduction}

Graves' orbitopathy (GO) is an autoimmune orbital inflammation that is most often associated with autoimmune hyperthyroidism

*shares last authorship in Graves' disease (GD), which is a common autoimmune condition affecting about $1 \%$ of the population, mainly women [1].

TSH-receptor (TSHR) autoantibodies (TRAb) play a major role in the pathogenesis of GD [2]. Binding of stimulating antibodies leads to development of uncontrolled hyperthyroidism. Since 
orbital fibroblasts express higher levels of TSHR, TRAb have a direct impact on the development of orbitopathy. A cross talk between TSHR with IGF1-receptor signalling leads to an excess hyaluronanacid production and consequent fibrosis [3]. Furthermore, binding of TRAb induces adipogenesis with resultant proptosis [4]. The central role of the TSHR for the pathogenesis of Graves' orbitopathy (GO) has also been shown shown in experimental animal models which use genetic or adenovirus immunization against TSHR to induce autoimmune hyperthyroidism with similar pathological features to human orbitopathy [5-7].

Clinically Graves' orbitopathy is a highly variable disease [8]. Most of the patients develop mild stages. However, $20-30 \%$ of GO patients develop more severe stages and 3-6\% even sight threatening disease. Patients with advanced stages of GO have a low quality of life due to changed appearance, diplopia, and visual acuity reduction [9]. Treatment decisions are based on activity and severity of the disease [10-12]. However, there is still uncertainty about the duration and intensity of therapy.

Over the past several decades, many papers have been published about the usefulness of thyrotropin receptor antibodies level measurements in relation to diagnosis and treatment of GO (summarized in $[13,14])$.

TRAbs can be quantified with binding immunoassays of colorimetric or chemiluminescent end-point detection, competition by TSHR ligand or monoclonal antibody or bridge formation between two recombinant TSHR constructs involving an immobilized capture and a labelled reporter. Functional bioassays measure TSHR $G$-protein signaling on live cells engineered to measure either the increased cAMP of stimulating immunoglobulins (TSAb) or decreased cAMP of blocking immunoglobulins (TBAb) $[15,16]$. There is still an ongoing matter of debate if results of binding or bioassays are more relevant for treatment decisions.

Seo at al. (2018) [13] have presented in their article a very careful summary, that duration of the disease, the accompanying therapy of hyperthyroidism and even nationality affect the TRAb levels and their interpretability.

The aim of this clinical study was to identify the practical usefulness of serial TRAb level measurements and to define variable cut off levels (cave: difference to the commercially provides cut offs for diagnostic assay sensitivity), which can predict mild or severe course of GO for the today available latest assay technologies. The analyzed patient cohort represents the clinical situation of everyday clinical use in a tertiary reference centre. Furthermore, this study also provides information on whether a bioassay has a significant added value compared to conventional binding assays.

\section{Patients and Methods}

\section{Patients}

The University Duisburg Essen Data base and Biobank for Patients with GD was founded in 2000 to collect data from our joint thyroid eye clinic. The analysis of TRAbs using 3rd generation assay by Roche began in 2007 and patients were consecutively included in this clinical trial since then up to 2017. Samples were taken at every patient appointment. This differed in number and frequency per individual patient. To establish a temporal reference for retrospec- tive analysis, the examination visits were summarized to specific time periods: Timepoint 1 (TP1) $=0-4$ months TP $2=5-8$ months, TP 3 = 9-12 months, TP $4=13-16$ TP 5 17-20 months, and TP 6 21-24 months after $\mathrm{GO}$ onset. According to the individual variable patient appointments data and sera were not available from all patients at all time points.

Patients were included in this study if their initial visit occurred within the first 6 months of the onset of eye disease. All patients had an untreated GO at first visit. Patients were treated according to the consensus statements of EUGOGO [10-12]. In case of active GO they were treated with i. v. steroids in combination with orbital irradiation if motility impairment was present. They were reevaluated after 6 weeks and 12 weeks. In case of persisting activity a few of the patients received off label immunosuppressive therapy. Bony orbital decompression was performed in patients with therapy resistant dysthyroid optic neuropathy as emergency. Later in inactive stages rehabilitative ophthalmic surgery was performed to restore appearance and function.

Grading of GO severity was done according to the modified NOSPECS score 0-6 [17]. [NOSPECS: no signs or symptoms (N); only sign lid retraction, no other symptoms $(\mathrm{O})$; soft tissue involvement $(\mathrm{S})$; proptosis $(\mathrm{P})$; eye muscle involvement $(\mathrm{E})$; corneal involvement $[\mathrm{C}]$; and sight loss due to optic nerve compression (S)]. The classification into mild and severe GO was performed at time point 3 after 9-2 months of disease duration before any of the surgical rehabilitation started. We discriminated between mild GO (NOSPECS $<5$ ) and severe GO (NOSPECS $\geq 5$ ). Patients with DON were assigned to severe course.

At first visit antithyroid drugs (ATD) were administered to 202 of 238 (85\%), 10 patients developed GO after thyroidectomy, and 25 patients developed GO after radioiodine therapy. During the observation period a 120 patients received definitive treatment of the thyroid (105 thyroidectomy, 17 radioiodine therapy).

\section{Assay technologies}

The Elecsys Anti-TSH Receptor (TRAb) electro-chemiluminescent immunoassay (Roche Diagnostics, Mannheim, Germany) on Cobas E411 platform is the assay, which is used for the clinical routine at the University Duisburg-Essen. The TRAb assay by Roche is a competitive binding immunoassay, also named TSH binding inhibition immunoglobulin (TBII) assay, using the M22 monoclonal antibody which binds TSHR with high affinity. Therefore, the assay determines the competition for binding to TSHR between the TRAbs and the antigen binding fragments (Fab) of antibodies labelled with ruthenium [18]. Hence, TRAb levels are assessed indirectly via the quantification of the bound antibodies. The measured luminescence signal is inversely proportional to the TRAb-Level. The TBII assay does not distinguish between blocking and stimulating immunoglobulins [19]. Here, the highest sensitivity (99\%) and specificity (99\%) values to diagnose GD could be calculated at a cut off level of $1.75 \mathrm{IU} / \mathrm{I}[20,21]$. According to the product insert the functional sensitivity was $0.9 \mathrm{IU} / \mathrm{l}$ and the detection limit was $0.3 \mathrm{IU} / \mathrm{l}$.

The IMMULITE 2000 TSI Assay operates in a two-step automated chemiluminescent immunoassay by binding a tandem pair of recombinant human TSH receptors in bridge formation. It consists of a bridge link between TRAbs and the two receptors (capture and signal antibodies) [22]. The capture receptor is characterized by a 
THSR chimera of the rat luteinizing hormone/chorionic gonadotropin receptor $(\mathrm{LH} / \mathrm{CG})$. That implies that the receptor has epitopes, which should be recognized only by TSAb [22]. The binding receptor is immobilized on a solid phase. TSI binds to these during a 30-minute incubation period. After centrifugal purification of the supernatant, in the second step the signal receptors are added for 30 minutes, which bind to the second arm of the complexed TSI. These receptors are labelled with alkaline phosphatase, thereby converting an added chemiluminescent substrate in the last step. The generated light signal is detected with the result that the quantity of TSI is directly correlated to the assessed chemiluminescent signal. A new automated assay for the detection of stimulating TRAb with this bridge technology has been developed. At a cut off level of $0.55 \mathrm{IU} / \mathrm{I}$ the highest sensitivity (100\%) and specificity (about 99\%) were seen for diagnosing GD [23, 24]. The assay is calibrated using the WHO 2nd international standard (IS) for thyroidstimulating antibodies (NIBSC 08/204).

The bioactivity of TSH-receptor stimulating antibodies (TSAb) were assessed with the cell-based bridging bioassay Thyretain (Quidel Corp., San Diego, CA) according the manufacturer's instructions [25]. The assay uses Chinese hamster ovary ( $\mathrm{CHO}$ ) cells expressing a chimeric TSH-R (MC4) and CAMP-dependent luciferase expression. Percentages of specimen-to-reference ratio (SRR\%) values were calculated according the following formula: SRR \% = average TSAb specimen relative light units/average reference standard relative light units $\times 100$.

All three assays were performed following the manufacturer's instructions. Due to the continuous development of the test methods for the determination of TSH receptor antibodies, these can increasingly be used as measurable parameters of biochemical processes and have an even better diagnostic and prognostic value.

\section{Statistical analysis}

Data were collected by using Microsoft Office Excel (Version: 2016). For metric data, median values and range or the mean and standard deviation (SD \pm ) were calculated and differences were evaluated with Student's $t$-test (two-tailed) if D'Agostino-Pearson omnibus normality test showed normal distribution, if not, with Mann-Whitney test. Fisher's exact test and the Chi²-test were used to evaluate group distributions of binary variables (e. g., gender, prior anti-inflammatory therapy). All calculations were performed with GraphPad Prism (Prism 6 for Windows, Software Inc., San Diego, CA, USA, Version 6.01). Receiver operator curve (ROC) analysis was performed and analyzed to select the best cut off with highest clinical sensitivity and specificity. The probability of correct identification of mild or severe GO was preferred (specificity set to $90 \%)$ over a higher sensitivity (probability of detection). A twotailed $p$-value $<0.05$ was considered to be statistically significant.

\section{Ethics statement}

The research protocols were reviewed and approved by the Institutional ethics commission (06-3211 and 14-5965-BO), and written informed consent was obtained from all study participants. All experiments have been conducted according to the principles expressed in the Declaration of Helsinki.

\section{Results}

\section{Patient characteristics}

- Table 1 summarizes key patient characteristics of the cohort. The mean age at the time of first manifestation of $\mathrm{GO}$ was 46 years in the mild GO group and 52 years in the severe GO group ( $p<0.0001)$. Most of the patients developed GO within 6 months of the onset of thyroid disease (70\% mild GO and $69 \%$ severe GO). Patients with

$\checkmark$ Table 1 Patients characteristics.

\begin{tabular}{|c|c|c|c|}
\hline & Mild GO & Severe GO & p-Value \\
\hline Number $(n=238)$ & $103(42 \%)$ & 135 (58\%) & \\
\hline Age & $46(23-74)$ & $52(20-77)$ & $<0.0001$ \\
\hline Sex & & & 0.0799 \\
\hline Male & 12 & 28 & \\
\hline Female & 91 & 107 & \\
\hline Duration of thyroid disease at beginning of $\mathrm{GO}$ (months) & 0 (Min 12 Max 136) & 1.5 (Min 5 Max 373) & n.s. \\
\hline \multicolumn{4}{|l|}{ Thyroid therapy at beginning of GO } \\
\hline ATD & 94 & 107 & n.s. \\
\hline Thyroid surgery & 6 & 6 & n.s. \\
\hline Radioiodine & 3 & 22 & 0.001 \\
\hline Steroid therapy & 57 & 116 & $<0.0001$ \\
\hline Orbital radiation & 19 & 84 & $<0.0001$ \\
\hline Eye surgery & 12 & 80 & $<0.0001$ \\
\hline Decompression & 3 & 51 (17 DON) & $<0.0001$ \\
\hline
\end{tabular}




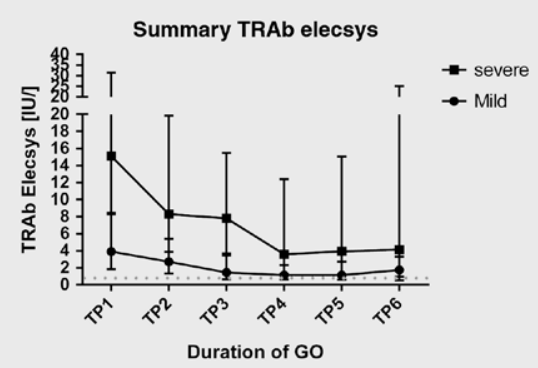

b

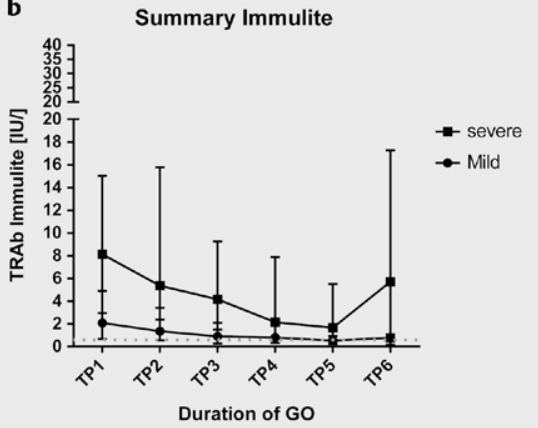

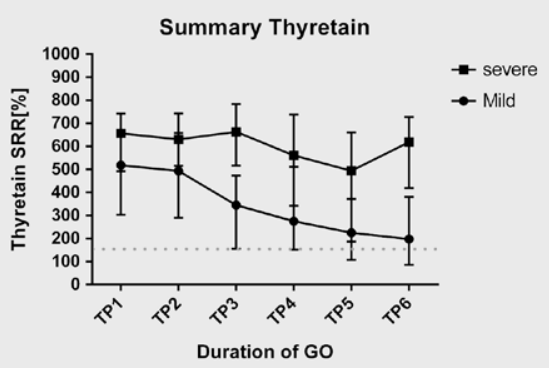

Fig. 1 Antibody levels over a 2-year follow-up period of patients with mild course of $\mathrm{GO}$ (dots) and patients with a severe course of $\mathrm{GO}$ (rectangles) measured with TSH-R-Ab Elecsys 2A, IMMULITE bridge assay (2B), and with TSI Thyretain bioassay (2C) assay. Shown are median (line) and interquartile range (whiskers). TRAb levels decrease continuously during the follow up in patients with mild GO (lower curves - dots). Patients with severe course of GO have persisting high TRAb levels (upper curves - rectangles) over the whole course of GO. The median even increases at the last timepoint. The increase is caused by the patient fraction with relapses of the hyperthyroidism during follow up.
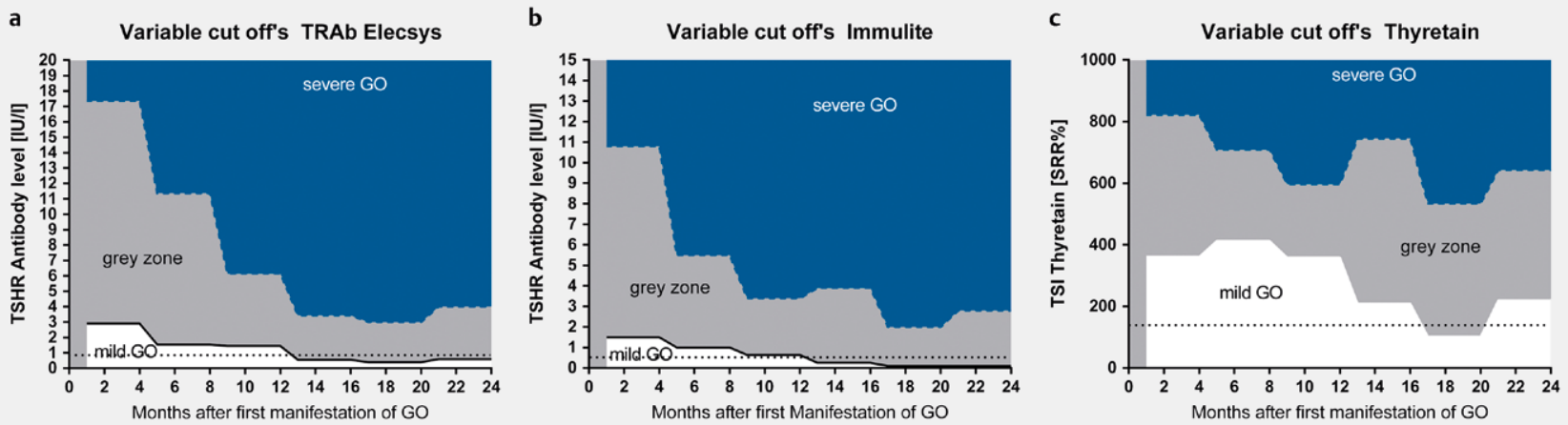

- Fig. 2 Variable cut off curves. All cut off are plotted against the duration of $G O$ over the time period of 24 months for TRAb elecsys a and TRAb IMMULITE $\mathbf{b}$ and the TSAb bioassay Thyretain $\mathbf{c}$. Black: Area of TRAB levels, which support the prognosis of a severe course of GO black. White: Area of TRAB levels, which support the prognosis of mild course of GO white. Grey: So called grey zone - TRAb levels in this area can not be used for prognostic statements.

severe and mild $\mathrm{GO}$ had similar duration of hyperthyroidism proceeding GO, that is, no significant differences. Some patients developed GO later in the course of thyroid disease ( $25 \%$ of severe $\mathrm{GO}$ vs. $12 \%$ of mild $\mathrm{GO})$. Among these were patients after radioiodine therapy (RJT $n=3$ mild $G O$ and $n=22$ severe $G O ; p=0.001)$. According to the consensus statements of EUGOGO patients with severe $\mathrm{GO}$ received significantly more often anti-inflammatory treatment, emergency decompression and other surgical rehabilitative measures.

\section{Positivity of TRAb measurements according to the commercially provided diagnostic cut offs of the applied assays}

Within the first four months (timepoint 1 ) of GO positive TRAb levels could be measured in most of the GO patients with all three assays: $88 \%$ TSH-R-Ab Elecsys binding assay, $90 \%$ IMMULITE bridge assay and $97 \%$ with Thyretain bioassay. During the follow up TRAb levels decrease (see > Fig. 2). After two years GO duration: positive TRAb levels can be still measured with the Thyretain assay in $81 \%$ of the patients, while the other test systems are less sensitive: IMMULITE bridge assay (71\%) and TSH-R-Ab Elecsys (61\%). The Thyretain bioassay was significantly more sensitive in measuring positive TSH receptor antibody levels over the whole observation period.

\section{Levels of antibody measurements during the first 2 years after manifestation of GO}

The levels of antibody measurements during the first 2 years after manifestation of $\mathrm{GO}$ is displayed for all three assay systems in $>$ Fig. 1a-c. Median and 25 and $75 \% \mathrm{Cl}$ are shown. The size of the error bars indicate the broad distribution among the individual patients. At all times, the levels of antibody measured with all three assays differed significantly between mild and severe GO. This significant difference of the antibody levels encouraged towards a ROC plot analysis to define variable cut off levels for prognosis towards mild or severe GO. Antibody levels measured with IMMULITE test and the Thyretain test increased at the last measured TP 6 (21-24 months after the onset of $\mathrm{GO}$ ) in the group of severe GO. This increases was caused from the patient fraction, who at that time suf- 
- Table 2 Variable cut offs for prognostic statements towards a mild or severe course of GO for TRAb elecsys.

\section{TSH-R-Ab Elecsys}

\begin{tabular}{|c|c|c|c|c|c|c|c|}
\hline \multirow[b]{2}{*}{$\begin{array}{l}\text { Timepoint } \\
\text { after onset } \\
\text { of GO }\end{array}$} & \multirow[b]{2}{*}{$\begin{array}{l}\text { ROC plot Area } \\
\text { under the curve }\end{array}$} & \multicolumn{3}{|c|}{ Variable cut offs for severe course } & \multicolumn{3}{|c|}{ Variable cut offs for mild course } \\
\hline & & $\begin{array}{l}\text { Cut off level } \\
\text { (IU/I) }\end{array}$ & $\begin{array}{l}\text { Sensitivity (\%) } \\
\text { (95\% } \\
\text { Confidence } \\
\text { Interval) }\end{array}$ & $\begin{array}{l}\text { Likeli- } \\
\text { hood } \\
\text { ratio }\end{array}$ & $\begin{array}{l}\text { Cut off level } \\
\text { (IU/I) }\end{array}$ & $\begin{array}{l}\text { Sensitivity (\%) } \\
\text { (95\% } \\
\text { Confidence } \\
\text { Interval) }\end{array}$ & $\begin{array}{l}\text { Likeli- } \\
\text { hood } \\
\text { ratio }\end{array}$ \\
\hline 1 & $0.80(p<0.0001)$ & 17.4 & $44.9(30.7-59.8)$ & 4.5 & 3.6 & $45(32.1-58.4)$ & 4.4 \\
\hline 2 & $0.76(p<0.0001)$ & 11.6 & $40.6(30.9-50.8)$ & 4.5 & 1.5 & $32.5(22.2-44.1)$ & 3.3 \\
\hline 3 & $0.81(p<0.0001)$ & 6.2 & $58.1(48.1-67.7)$ & 6.0 & 1.4 & $46.7(33.9-59.9)$ & 4.9 \\
\hline 4 & $0.74(p<0.0001)$ & 4.9 & $43.6(30.3-57.7)$ & 4.4 & 0.5 & $15.0(5.7-29.8)$ & 1.7 \\
\hline 5 & $0.73(p=0.0029)$ & 3.1 & $55.9(37.9-72.8)$ & 4.7 & 0.4 & $16(4.5-36.1)$ & 1,6 \\
\hline 6 & $0.73(p=0.013)$ & 5.1 & $47.4(24.5-71.1)$ & 4.5 & 0.6 & $31.6(12.6-56.5)$ & 3 \\
\hline
\end{tabular}

- Table 3 Variable cut offs for prognostic statements towards a mild or severe course of GO for TRAb IMMULITE.

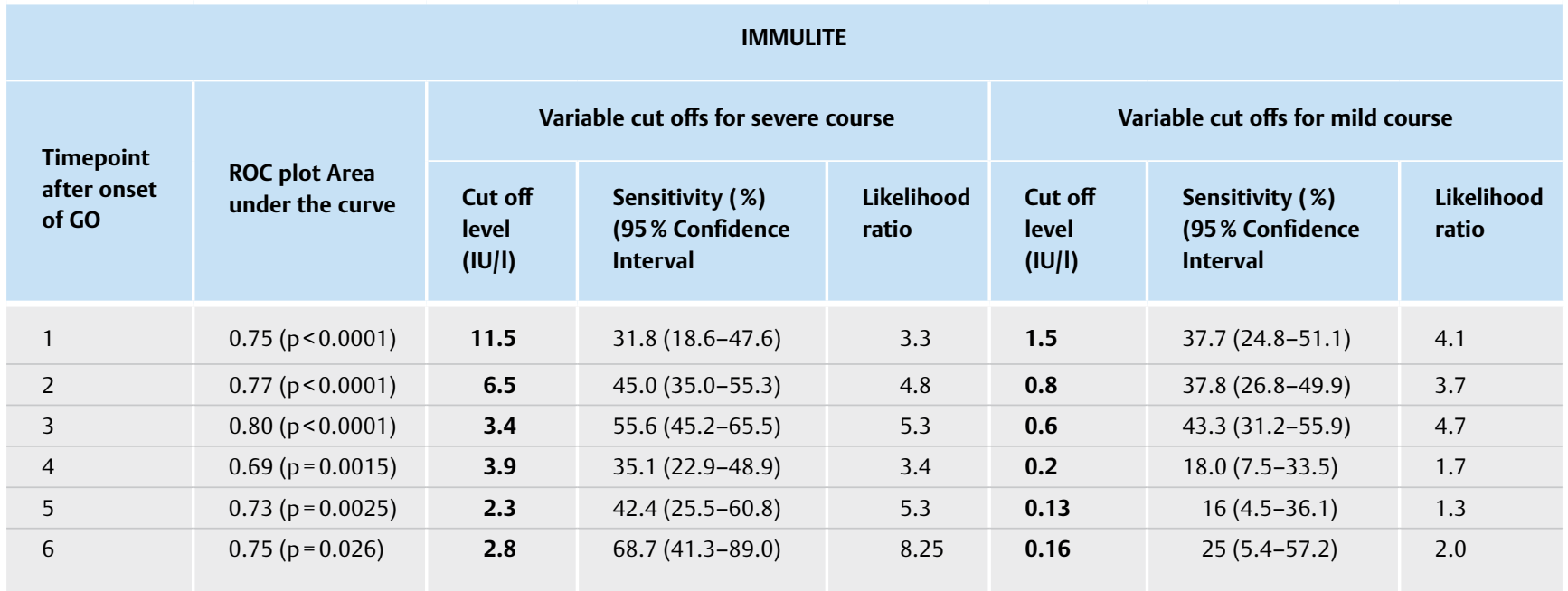

fered from a relapse of hyperthyroidism after discontinuation of antithyroid drug therapy and as a result of radioiodine therapy.

\section{ROC plot analysis}

ROC plot analysis was performed to select variable cut off levels for prognosis. For the selection of cut off level for severe course of $\mathrm{GO}$ - TRAb levels of mild GO were used as controls and for the selection of cut off levels for mild GO - TRAb levels of severe GO were used as controls. The area under the curve with significance level is displayed in the second row of each Table for the three assays tested. Cut off levels were selected at a specificity levels of $90 \%$. As expected the sensitivity levels varied for each cut off at $90 \%$ specificity for each selected timepoint for mild and severe prognosis.

Cut offs for all six time points are shown in > Tables 2-4 for all three assay systems. All defined cut off levels have been grouped into threshold curves for practical use in patients ( $\mathbf{F i g}$. 2 a-c). The values of the patient can be drawn directly into one of the three diagramms depending on the assay type applied in the respective clinic. The white area in the middle indicates the range of values for which no accurate predictions can be made.

\section{Variable cut offs for TRAb Elecsys Assay}

Variable cut off levels for mild and severe prognosis are displayed in > Fig. 2a. The sensitivity for the selected cut offs at $90 \%$ specificity varied and reached highest values at the timepoints 2, 3, and 4. The sensitivity for predictions of a severe course was $41 \%, 58 \%$, $44 \%$ for timepoint 2, 3, and 4, respectively, and were higher than for the predictions of a mild course: $32 \%, 47 \%, 15 \%$ for timepoint 2,3 and 4 respectively. To give an example: 5-8 months after the beginning of $\mathrm{GO}$ the risk of a severe course of $\mathrm{GO}$ can be detected in $41 \%$ of the affected patients according to a cut off of TRAB Elecsys above $11.6 \mathrm{IU} / \mathrm{l}$. So a patient with TRAb above $11.6 \mathrm{IU} / \mathrm{I} 5-8$ months after the beginning of $\mathrm{GO}$ has a 4.5 times higher risk of a severe course of GO in comparison to patients with lower TRAb 
- Table 4 Variable cut-offs for prognostic statements towards a mild or severe course of GO for TSAb bioassay Thyretain.

\begin{tabular}{|c|c|c|c|c|c|c|c|}
\hline \multicolumn{8}{|c|}{ TSI Thyretain } \\
\hline \multirow{2}{*}{$\begin{array}{l}\text { Timepoint } \\
\text { after onset } \\
\text { of GO }\end{array}$} & \multirow[b]{2}{*}{$\begin{array}{l}\text { ROC plot Area } \\
\text { under the curve }\end{array}$} & \multicolumn{3}{|c|}{ Variable cut offs for severe course } & \multicolumn{3}{|c|}{ Variable cut offs for mild course } \\
\hline & & $\begin{array}{l}\text { Cut off } \\
\text { level } \\
\text { (IU/I) }\end{array}$ & $\begin{array}{l}\text { Sensitivity (\%) } \\
\text { (95\% Confidence } \\
\text { Interval) }\end{array}$ & $\begin{array}{l}\text { Likelihood } \\
\text { ratio }\end{array}$ & $\begin{array}{l}\text { Cut off } \\
\text { level } \\
\text { (IU/I) }\end{array}$ & $\begin{array}{l}\text { Sensitivity (\%) } \\
\text { (95\% Confidence } \\
\text { Interval) }\end{array}$ & $\begin{array}{l}\text { Likelihood } \\
\text { ratio }\end{array}$ \\
\hline 1 & $0.64(p=0.016)$ & 822 & $8.9(2.5-21.2)$ & 1.0 & 361 & $30.6(19.6-43.7)$ & 2.8 \\
\hline 2 & $0.69(p<0.0001)$ & 714 & $31.3(22.3-41.4)$ & 3.4 & 402 & $36.8(26.1-48.7)$ & 4.1 \\
\hline 3 & $0.84(p<0.0001)$ & 616 & $58.2(47.8-68.1)$ & 6.3 & 353 & $50.8(38.1-63.4)$ & 5.5 \\
\hline 4 & $0.72(p=0.0003)$ & 745 & $24.1(13.5-37.6)$ & 2.3 & 188 & $31.6(17.5-48.7)$ & 3.4 \\
\hline 5 & $0.72(p<0.0039)$ & 582 & $35.3(19.7-53.5)$ & 3.2 & 102 & $22.2(8.6-42.3)$ & 1.9 \\
\hline 6 & $0.84(p=0.0003)$ & 643 & $39.0(17.3-64.2)$ & 4.9 & 189 & $47.4(24.4-71.1)$ & 4.2 \\
\hline
\end{tabular}

levels. If at that time the TRAb level were below $1.5 \mathrm{IU} / \mathrm{I}$ - that means already negative than the patient has a 3.3 times better chance of a mild course. The exact cut off values and likelihood values are given in $>$ Table 2.

\section{Variable cut offs for the IMMULITE assay}

Variable cut off levels could be calculated in the same way for the TRAb IMMULITE assay. Comparable sensitivity values were reached. The sensitivity for predictions of a severe course were $45 \%, 55 \%$, $35 \%$ for timepoint 2, 3, and 4, respectively, were also higher than for the predictions of a mild course: $38 \%, 43 \%, 18 \%$ for timepoint 2,3 , and 4, respectively. All cut of levels are graphically displayed in $\mathbf{F i g . ~} \mathbf{2 b}$. At the usual timepoint when patients were refered to tertiary referral centers between 5-8 months after $\mathrm{GO}$ onset patient is in the risk zone if TRAb measured with the IMMULITE were still above 6.5 (with a likelihood of 4.8). If TRAb are measured just above the diagnostic cut off and are below $0.8 \mathrm{IU} / \mathrm{I}$ than it can be prognosed with $90 \%$ specificity that the patient is going to have a mild course with a likelihood of 3.7. The exact cut off values and likelihood values are given in $>$ Table 3.

\section{Variable cut offs for the Thyretain assay}

Variable cut off levels could be calculated in the same way for the Thyretain bioassay. The sensitivity for predictions of a severe course were sligthly lower for timepoint 2 and 4 in comparison to Elecsys and IMMULITE Assay: 31 \%, 58\%, 24\% for timepoint 2, 3, and 4, respectively. However, on the other side, slighly higher sensitivity rates were reached for the prediction of the mild course: $37 \%, 51 \%$, $32 \%$ for the most important timepoints 2, 3, and 4, respectively. All values are given in $>$ Table 4 . To give an example: 5-8 months after the beginning of GO, if specimen-to-reference ratio (SRR \%) is still above $714 \%$ than there is a 3.4 times higher likelyhood to develop a severe course of $G O$. If the SRR is $<402$ there is a 4.1 times likelyhood to develop a mild course of $\mathrm{GO}$. For the range in between these two cut offs, there is a grey zone were no predictions are possible.

\section{Discussion}

Individual cut off levels for the chance of a mild course and the risk of a severe course of Graves' orbitopathy can be defined for all tested assay systems for different timepoints during course of the disease. For the precision of predictions the specificity was always set to $90 \%$. Therefore the probability of detection (sensitivity) varied between the timepoints. For the prediction of the severe course of GO all three tests delivered comparable detection rates. For the prediction of a mild course the bioassay reached higher detection rates in comparison to Elecsys and IMMULITE assay. The bioassay has also the highest rates of test positivity during the whole observation period.

We were aware of our group heterogeneity concerning treatment of hyperthyroidism at different timepoints. Antithyroid drug therapy lead to a continuous decay of $\operatorname{TRAb}[26,27]$ especially in patients who go into remission, who also have a better prognosis of their GO [28]. High TRAb in patients with poorly controlled hyperthyroidism can drop after thyroidectomy [29]. TRAb can enormously increase after Radioiodine therapy [26]. We have not excluded patients with thyroidectomy and radioiodine therapy on purpose since we would like to test the assay systems at a typical incidence cohort of a tertiary referral center. In our group there have been a few patients were GO manifested after thyroidectomy ( 6 and 5 in each group, respectively) and several patients with GO manifested after radioiodine therapy ( 3 in the mild group and 22 in the severe group). Here it could be clearly confirmed again that radioiodine therapy is associated with rather more severe stages of GO.

The predictive power of the third-generation TBII assay TRAK Elecsys, the bridge assay IMMULITE and Mc4-TSI Thyretain bioassay were comparable for the prediction of severe course of $G O$. This is in accordance to a similar structured study by jang et al. [30] who compared the third-generation TBII assay TRAK Elecsys and Mc4TSI Thyretain bioassay. They estimated the risk for severe GO in newly diagnosed GO patients (no previous treatment with steroids or radiation) with duration of GO no longer than 6 months (means 
within our timepoints 1 and 2). The cutoff values for the prediction of severe course of the third-generation TBII and Mc4-TSI assays were $10.67 \mathrm{IU} / \mathrm{I}$ and $555.10 \%$, respectively, with assay specificities of 84.9 and $89.0 \%$. These cut offs were comparibely to our for TRAb Elecsys (11.6 IU/I) and considerably lower for Thyretain (714\%). By looking on the duration of Graves hyperthyroidism at diagnosis of $\mathrm{GO}$ it can be seen that duration was significantly longer in comparison to our group ( 6 and 10 months in comparison to 0 and 1,5 months in our group. This may explain the lower cut off levels. So duration of antithyroid treatment should probably be taken into account for applying the cut off levels.

With our study we could confirm our earlier study [31], where we applied the second generation TBII assay based on the human recombinant TSH-receptor [32] (TRAK human LIA, B.R.A.H.M.S AG, Hennigsdorf/Berlin, Germany) in a comparable study design. The calculated predicting cut off's for the TRAb Elecsys assay herein were comparable to the 2006 published cut off levels for the second generation TRAb assay [31] (TP2 new 11.37 versus 8.8; TP3 new 6.15 vs. 5,1, TP4 new 4.8 vs. 3.4).

Other groups added additional cut off levels for TRAB and TSI. Lantz et al. (2014) found in a large incidence cohort of GD patients in Malmö (Sweden) that the proportion of patients with GO increased above the median $6.3 \mathrm{IU} / \mathrm{l}$ at diagnosis of GD and that $87 \%$ of patients who developed GO after GD diagnosis had TRAb (above 6.3 IU/land/or antiTPO below $20 \mathrm{kIU} / \mathrm{L}$ [33]. TRAb were measured with human radioreceptor assay kit (B.R.A.H・M·S sFlt-1 KRYPTOR assay).

Takakura et al. (2015) reported mean initial TSI values of 421.3 in those that developed orbitopathy compared to 245.9 in those who had at least 6 months of documented follow-up and did not develop orbitopathy $(p=0.04)$. Those in the top tercile of initial TSI values were 14 times as likely to develop orbitopathy [34].

Many other studies do not deliver cut off levels but provide strong further evidence that TRAb levels measured by binding assays or bioassays are correlated to GO activity and severity [17, 3539]. Depending on the composition of the studied cohorts the strengths of the correlations vary and sometimes the bioassay is superior to the binding assay and sometimes vice versa. Most of the studies confirm the higher the quartiles of the antibody levels the stronger are the manifestations of $\mathrm{GO}$ or the higher is the probability to develop GO during the course of GD.

All our defined cut off levels have been grouped into threshold curves for practical use in the clinical routine. In the course of the treatment of the GO, decisions have to be made again and again for the patients. Identification of relapsing hyperthyroidism was possible with automated immunoassays and cell-based bioassay especially with serial TRAb measurements during the course of ATD therapy [40] . Bartalena et al. (2017) has shown in the dose finding study for i. v. glucocorticoid treatment that after 6 weeks treatment one can already see a trend whether i. v. glucocorticoid treatment will deliver the desired treatment success [41]. TRAb levels in the risk area can be an additional argument at this time to decide whether the patient needs additional immunosuppressive therapy or not. Another example are late stage but yet untreated patients with some signs of activity here a TRAb value in the risk area would also help to opt for decision towards anti-inflammatory treatment.
On the other hand, often the ophthalmologist receives considerable pressure of suffering patients, which clinically classified as mild GO. A prognostic marker will clearly help towards the decision to wait under selenium supplementation [42]. So in such a situation the cut offs for a mild course of GO can be applied and help the doctor to opt for a wait-and-see behavior. Here, the Thyretain assay offers a higher sensitivity in comparison to the binding assays.

Applying the results of tested assay sensitivity values $[15,23,43]$. In addition, the Thyretain assay delivered the highest positivity ratios over the whole course of the two year follow up. These high test sensitivity of bioassay have been reported previously, including GO patients with autoimmune thyroiditis [44-46].

\section{Conclusion}

Follow up measurements of TRAb deliver additional information on the probable risk for mild or severe course of $\mathrm{GO}$ and are therefore beneficial for the disease management. All three tested assays systems deliver comparable sensitivity rates for the predictions. Thyretain bioassay is slightly more sensitive than the automated binding immunoassays for the prediction of the mild course of $\mathrm{GO}$. The prognostic sensitivity is low in the first 4 months and increases considerably after 5 months of GO duration.

\section{Acknowledgements}

We thank M. Horstmann (Department for Molecular Ophthalmology, Essen, Germany) for blood specimen and data collection as well as U. Kaiser (Department of Ophthalmology, Essen, Germany). We thank Ashley Brown, Jennifer Holliday, and Ron Lollar of Quidel, Athens Ohio USA for their technical excellence in performing the Thyretain bioassay. This study was supported by the Junior Clinician Scientist program of the University Medicine Essen Clinician Scientist Academy (UMEA).

\section{Conflict of Interest}

M.S., M.O., D.Z., L.M., A.S., N.B., D.F., U.B.P., J.P.B, S.P. and A.E. have nothing to disclose. S.L. consults for Quidel.

\section{References}

[1] Ehlers M, Schott M, Allelein S. Graves' disease in clinical perspective. Front Biosci (Landmark Ed) 2019; 24: 35-47

[2] Bahn RS. Current Insights into the Pathogenesis of Graves' Ophthalmopathy. Horm Metab Res 2015; 47: 773-778

[3] Krieger CC, Neumann S, Gershengorn MC. TSH/IGF1 receptor crosstalk: Mechanism and clinical implications. Pharmacol Ther 2020; 107502

[4] Gortz GE, Moshkelgosha S, Jesenek C et al. Pathogenic Phenotype of Adipogenesis and Hyaluronan in Orbital Fibroblasts From Female Graves' Orbitopathy Mouse Model. Endocrinology 2016; 157: 3771-3778 
[5] Berchner-Pfannschmidt U, Moshkelgosha S, Diaz-Cano S et al. Comparative assessment of female mouse model of Graves' orbitopathy under different environments, accompanied by proinflammatory cytokine and T cell responses to thyrotropin hormone receptor antigen. Endocrinology 2016; 157: 1673-1682

[6] Moshkelgosha S, So PW, Deasy N et al. Cutting edge: retrobulbar inflammation, adipogenesis, and acute orbital congestion in a preclinical female mouse model of Graves' orbitopathy induced by thyrotropin receptor plasmid-in vivo electroporation. Endocrinology 2013; 154: 3008-3015

[7] Johnson KT, Wiesweg B, Schott $\mathrm{M}$ et al. Examination of orbital tissues in murine models of Graves' disease reveals expression of UCP- 1 and the TSHR in retrobulbar adipose tissues. Horm Metab Res 2013; 45: 401-407

[8] Uddin JM, Rubinstein T, Hamed-Azzam S. Phenotypes of Thyroid Eye Disease. Ophthalmic Plast Reconstr Surg 2018; 34: S28-S33

[9] Ponto KA, Merkesdal S, Hommel G et al. Public health relevance of Graves' orbitopathy. J Clin Endocrinol Metab 2013; 98: 145-152

[10] Bartalena L, Baldeschi L, Boboridis K et al. The 2016 European Thyroid Association/European Group on Graves' Orbitopathy Guidelines for the Management of Graves' Orbitopathy. Eur Thyroid J 2016; 5: 9-26

[11] Bartalena L, Baldeschi L, Dickinson AJ et al. Consensus statement of the European group on Graves' orbitopathy (EUGOGO) on management of Graves' orbitopathy. Thyroid 2008; 18: 333-346

[12] Bartalena L, Baldeschi L, Dickinson A et al. Consensus statement of the European Group on Graves' orbitopathy (EUGOGO) on management of GO. Eur J Endocrinol 2008; 158: 273-285

[13] Seo S, Sanchez Robledo M. Usefulness of TSH receptor antibodies as biomarkers for Graves' ophthalmopathy: a systematic review. J Endocrinol Invest 2018; 41: 1457-1468

[14] Eckstein A, Esser J, Mann K et al. Clinical value of TSH receptor antibodies measurement in patients with Graves' orbitopathy. Pediatr Endocrinol Rev 2010; 7: 198-203

[15] Lytton SD, Schluter A, Banga PJ. Functional diagnostics for thyrotropin hormone receptor autoantibodies: bioassays prevail over binding assays. Front Biosci (Landmark Ed) 2018; 23: 2028-2043

[16] Ehlers M, Allelein S, Schott M. TSH-receptor autoantibodies: pathophysiology, assay methods, and clinical applications. Minerva Endocrinol 2018; 43: 323-332

[17] Eckstein AK, Plicht M, Lax H et al. Clinical results of anti-inflammatory therapy in Graves' ophthalmopathy and association with thyroidal autoantibodies. Clin Endocrinol (Oxf) 2004; 61: 612-618

[18] Autilio C, Morelli R, Locantore P et al. Stimulating TSH receptor autoantibodies immunoassay: analytical evaluation and clinical performance in Graves' disease. Ann Clin Biochem 2018; 55: 172-177

[19] Smith BR, Bolton J, Young $S$ et al. A new assay for thyrotropin receptor autoantibodies. Thyroid 2004; 14: 830-835

[20] Hermsen D, Broecker-Preuss M, Casati M et al. Technical evaluation of the first fully automated assay for the detection of TSH receptor autoantibodies. Clin Chim Acta 2009; 401: 84-89

[21] Schott M, Hermsen D, Broecker-Preuss M et al. Clinical value of the first automated TSH receptor autoantibody assay for the diagnosis of Graves' disease (GD): An international multicentre trial. Clin Endocrinol (Oxf) 2009; 71: 566-573

[22] Frank CU, Braeth S, Dietrich JW et al. Bridge Technology with TSH Receptor Chimera for Sensitive Direct Detection of TSH Receptor Antibodies Causing Graves' Disease: Analytical and Clinical Evaluation. Horm Metab Res 2015; 47: 880-888

[23] Allelein S, Ehlers M, Goretzki S et al. Clinical Evaluation of the First Automated Assay for the Detection of Stimulating TSH Receptor Autoantibodies. Horm Metab Res 2016; 48: 795-801
[24] Tozzoli R, D’Aurizio F, Villalta D et al. Evaluation of the first fully automated immunoassay method for the measurement of stimulating TSH receptor autoantibodies in Graves' disease. Clin Chem Lab Med 2017; 55: 58-64

[25] Lytton S, Li Y, Olivo P et al. Novel chimeric thyroid-stimulating hormone-receptor bioassay for thyroid-stimulating immunoglobulin. Clin Exp Immunol 2010; 162: 438-446

[26] Laurberg P, Wallin G, Tallstedt L et al. TSH-receptor autoimmunity in Graves' disease after therapy with anti-thyroid drugs, surgery, or radioiodine: A 5-year prospective randomized study. Eur J Endocrinol 2008; 158: 69-75

[27] Andrade VA, Gross JL, Maia AL. Serum thyrotropin-receptor autoantibodies levels after I therapy in Graves' patients: effect of pretreatment with methimazole evaluated by a prospective, randomized study. Eur J Endocrinol 2004; 151: 467-474

[28] Eckstein AK, Lax H, Losch C et al. Patients with severe Graves' ophthalmopathy have a higher risk of relapsing hyperthyroidism and are unlikely to remain in remission. Clin Endocrinol (Oxf) 2007; 67: 607-612

[29] Meyer Zu Horste M, Pateronis K, Walz MK et al. The Effect of Early Thyroidectomy on the Course of Active Graves' Orbitopathy (GO): A Retrospective Case Study. Horm Metab Res 2016; 48: 433-439

[30] Jang SY, Shin DY, Lee EJ et al. Relevance of TSH-receptor antibody levels in predicting disease course in Graves' orbitopathy: Comparison of the third-generation TBII assay and Mc4-TSI bioassay. Eye (Lond) 2013; 27: 964-971

[31] Eckstein AK, Plicht M, Lax $\mathrm{H}$ et al. Thyrotropin receptor autoantibodies are independent risk factors for Graves' ophthalmopathy and help to predict severity and outcome of the disease. J Clin Endocrinol Metab 2006; 91: 3464-3470

[32] Costagliola S, Morgenthaler NG, Hoermann R et al. Second generation assay for thyrotropin receptor antibodies has superior diagnostic sensitivity for Graves' disease. J Clin Endocrinol Metab 1999; 84: 9097

[33] Lantz M, Planck T, Asman P et al. Increased TRAb and/or low anti-TPO titers at diagnosis of graves' disease are associated with an increased risk of developing ophthalmopathy after onset. Exp Clin Endocrinol Diabetes 2014; 122: 113-117

[34] Takakura A, Kirkeby K, Earle K et al. Predicting the Development of Orbitopathy in Graves Thyroidopathy Patients: The Potential Role of TSI Testing. Ophthalmic Plast Reconstr Surg 2015; 31: 369-372

[35] Jang SY, Shin DY, Lee EJ et al. Clinical characteristics of Graves' orbitopathy in patients showing discrepancy between levels from TBII assays and TSI bioassay. Clin Endocrinol (Oxf) 2014; 80: 591-597

[36] Hiromatsu Y, Eguchi H, Matsuo Y et al. Role of a new bioassay for thyroid-stimulating antibodies (aequorin TSAb) in Graves' ophthalmopathy. Endocr J 2020; 67: 347-352

[37] Roos JCP, Paulpandian V, Murthy R. Serial TSH-receptor antibody levels to guide the management of thyroid eye disease: The impact of smoking, immunosuppression, radio-iodine, and thyroidectomy. Eye (Lond) 2019; 33: 212-217

[38] Lytton SD, Ponto KA, Kanitz M et al. A novel thyroid stimulating immunoglobulin bioassay is a functional indicator of activity and severity of Graves' orbitopathy. J Clin Endocrinol Metab 2010; 95: 2123-2131

[39] Woo Y], Jang SY, Lim TH et al. Clinical Association of Thyroid Stimulating Hormone Receptor Antibody Levels with Disease Severity in the Chronic Inactive Stage of Graves' Orbitopathy. Korean J Ophthalmol 2015; 29: 213219

[40] Stöhr M, Oeverhaus M, Lytton SD et al. Predicting the Relapse of Hyperthyroidism in Treated Graves' Disease with Orbitopathy by Serial Measurements of TSH-Receptor Autoantibodies. Horm Metab Res 2021; 53: 235-244 
[41] Bartalena L, Veronesi G, Krassas GE et al. Does early response to intravenous glucocorticoids predict the final outcome in patients with moderate-to-severe and active Graves' orbitopathy? J Endocrinol Invest 2017; 40: 547-553

[42] Marcocci C, Kahaly G], Krassas GE et al. Selenium and the course of mild Graves' orbitopathy. N Eng J Med 2011; 364: 1920-1931

[43] Hermsen D, Liu C, Domberg J et al. Comparison of a solid phase human- versus porcine- thyrotropin receptor-based immunoassay for the measurement of thyrotropin receptor antibodies in patients with thyroid diseases. Exp Clin Endocrinol Diabetes 2008; 116: S59-S63
[44] Kashiwai T, Tada $\mathrm{H}$, Asahi $\mathrm{K}$ et al. Significance of thyroid stimulating antibody and long term follow up in patients with euthyroid Graves' disease. Endocr J 1995; 42: 405-412

[45] Kahaly G], Diana T, Glang J et al. Thyroid Stimulating Antibodies Are Highly Prevalent in Hashimoto's Thyroiditis and Associated Orbitopathy. J Clin Endocrinol Metab 2016; 101: 1998-2004

[46] Khoo DH, Ho SC, Seah LL et al. The combination of absent thyroid peroxidase antibodies and high thyroid-stimulating immunoglobulin levels in Graves' disease identifies a group at markedly increased risk of ophthalmopathy. Thyroid 1999; 9: 1175-1180 